These findings show that the pyruvic derivatives of MIT and DIT are normal components of the thyroid. No indications are available to show if they arise from free or protein-linked iodotyrosines. Experiments are in progress to check the hypothesis that thyroxine could be synthesized in vivo from thyroglobulin DIT and free DIHPPA.

Biochimie Médicale, Faculté de Médecine et de Pharmacie, Marseille (France)

JoHn F. B. HANEY SERGE LISSITZKY

1 G. Hillman, Z. Naturforsch., IIb (I956) 424 .

2 R. 1. Meltzer and R. J. Stanaback, J. Org. Chem., 26 (I961) I977.

3 T. Shiba and H. J. Cahnmann, Biochim. Biophys. Acta, 58 (1962) 609.

4. Yip and S. J. KLebanoff, Endocrinol., 70 (I962) $93 \mathrm{I}$.

5 S. Lissitzky, J. Gregoire, J. Gregoire and N. Limozin, Gen. Comp. Endocrinol., i (196I) 5 I9.

6 S. Lissitzky and J. F. B. Haney, Arch. Biochem. Biophys., in the press.

7 M. Nakano, T. S. Danowski and A. Utsumi, Endocrinol., 65 (I959) 242.

Received July I2th, I962

* Post-Sophomore Research Fellow of the National Institutes of Health, U.S. Public Health Service.

Biochim. Biophys. Acta, 63 (1962) 557-559

PN II48

\title{
Identification of the allergen in ipecacuanha
}

Ipecacuanha, the powdered dried rhizome and roots of Cephaëlis ipecacuanha, has long been known to contain an extremely potent inhalant allergen. The inhalation of minute quantities of the dust of ipecac may cause rhinitis and asthma in persons specifically sensitized by frequent professional contact with the powder, e.g. pharmacists and their assistants. WIDAL, ABRAMI AND JOLTRAIN ${ }^{1}$ already pointed out that the reactions of these patients are of the anaphylactic or allergic type.

Accordingly, in view of the general chemical nature of inhalant allergens ${ }^{2}$, it seems reasonable to suspect the responsible allergen to be some kind of protein rather than the alkaloids contained in ipecac, which are mainly emetine and cephaëline. Indeed, Widal et al. ${ }^{1}$, and STORM VAN LEEUWEN ${ }^{3}$ demonstrated that patients hypersensitive to the dust of ipecac give negative skin reactions to emetine.

In an attempt to identify the active allergen we extracted $97 \mathrm{~g}$ of finely divided powdered ipecacuanha (Rio variety) with $800 \mathrm{ml} 0.9 \% \mathrm{NaCl}$ for $2 \mathrm{~h}$ at room temperature. The undissolved residue was removed by centrifugation and a small portion of the clear, reddish-brown extract, containing $30 \mathrm{mg}$ of dry substance per $\mathrm{ml}$, was kept for analysis and calculation of total activity.

Alkaloids and other compounds of low molecular weight were removed from the extract by extensive dialysis against water at $18^{\circ}$. The dialysed extract was dried by lyophilization and yielded $4.8 \mathrm{~g}$ of an easily soluble pink substance (A) which contained all the activity. A salting-out curve with ammonium sulphate at $\mathrm{pH} 7.0$. showed that the main protein constituent precipitated between $20-60 \%$ saturation at $4^{\circ}$ (Fig. I). This component was accordingly isolated in quantity from the crude product $A$ by ammonium sulphate fractionation at $4^{\circ}$. The brown precipitate was 
collected by centrifugation after $24 \mathrm{~h}$ standing; only a small amount of relatively unreactive substances could be recovered from the pale-yellow supernatant.

The precipitate was dissolved in the minimum amount of water and dialyzed until salt-free. Further purification was achieved by repeated precipitation from neutral aqueous solution with 2 vol. of ice-cold acetone. The final precipitate was dissolved in distilled water and dried by lyophilization. We obtained $2 \mathrm{~g}$ of a pink powder (Fraction B).

This product, together with other fractions obtained during the isolation procedure, was tested for skin reactivity in patients allergic to the dust of ipecac. Tests were performed by the intracutaneous injection of $0.1 \mathrm{ml}$ of dilute solutions in physiological buffers. Specific positive skin reactions were obtained with as little as

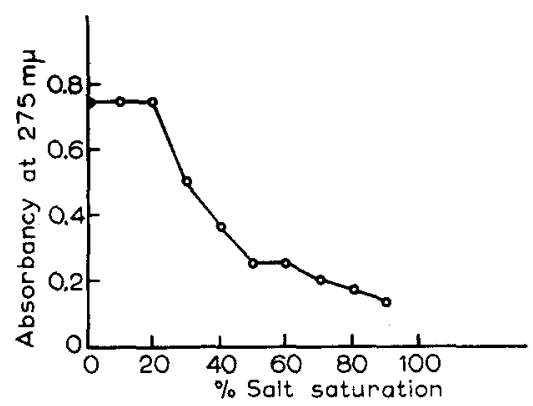

Fig. I. Salting-out curve at $\mathrm{pH} 7.0$ of a crude, dialyzed extract of ipecacuanha powder. Initial concentration, $0.5 \mathrm{mg}$ Substance $\mathrm{A}$ per $\mathrm{ml}$ at each $\left(\mathrm{NH}_{4}\right)_{2} \mathrm{SO}_{4}$ concentration. The tubes were allowed to stand for $24 \mathrm{~h}$ at $4^{\circ}$ before filtering off the precipitate and measuring the absorbancy of the supernatant solution.

o.or $\mu \mathrm{g}$ of Substance B; to give the same size of skin reaction, I $\mu \mathrm{g}$ of histamine was needed in these patients. Normal control persons gave negative skin reactions. The allergen was identified as a protein-carbohydrate complex, containing I0.4\% protein N (micro-Kjeldahl) and $8.5 \%$ reducing sugars (expressed as galactose), as determined with the orcinol reagent ${ }^{4}$. Hydrolysis and paper chromatography showed the protein to contain the amino acids Cys, Lys, Arg, Asp, Glu, Thr, Gly, Ser, His, Ala, Pro, Val, Leu, Ileu, Tyr, Phe and Try. In mild acid hydrolysates (o.I $N \mathrm{HCl}$ for $4 \mathrm{~h}$ at $\left(100^{\circ}\right)$ the monosaccharides galactose, glucose, arabinose and xylose could be identified on paper chromatograms.

The protein nature of the allergen is illustrated by its ultraviolet-absorption spectrum (Fig. 2). The purified allergen dissolves readily in water to give a clear reddish-brown solution; acidic solutions possess a pale-yellow colour, which changes into violet brown upon the addition of alkali to $\mathrm{pH}$ values above 7.5 . We have not yet been able to detect any bound plant pigments in the allergen. The allergenic protein compound may be precipitated from aqueous solution with an equal volume 
of ro $\%$ trichloroacetic acid, $5 \%$ sulphosalicylic acid and I \% picric acid. It is remarkably resistant towards heat treatment in acid solutions, less so in alkaline media.

The homogeneity of the allergen preparation was studied by electrophoresis and by ultracentrifugal analysis at different $\mathrm{pH}$ values. The compound migrates towards the anode on paper as one single, broad band in barbiturate buffer $(\mathrm{pH} 8.6)$, and towards the cathode in acetate buffer $(\mathrm{pH} 4.5)$ and in glycine- $\mathrm{HCl}$ buffer ( $\mathrm{pH} 2.4)$. The isoelectric point is at about $\mathrm{pH}$ 5.0-5.5. It is of interest to note that protein(Amidoblack) and carbohydrate (periodate-fuchsin) stains coincided exactly.

Ultracentrifugal measurements with the Spinco model E ultracentrifuge revealed one single peak in barbiturate buffer $(\mathrm{pH} 8.6, I$ o.I) as well as in acetate buffer $(\mathrm{pH} 5.6, I$ o. $)$, for which a sedimentation coefficient $\left(s_{20}\right)$ of 3.39 was calculated.

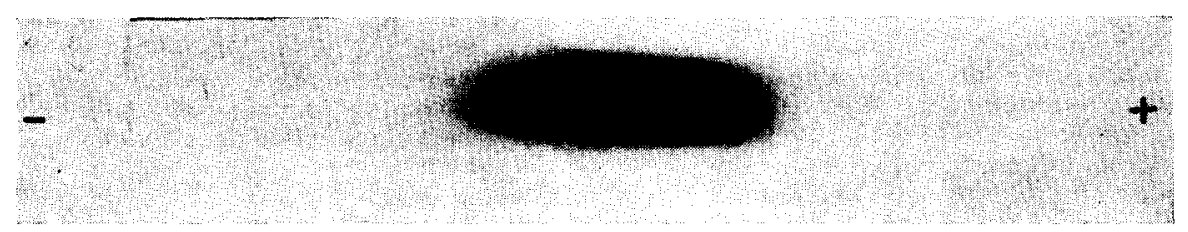

Fig. 3. Agar-gel electropherogram of purified ipecacuanha allergen Fraction $\mathrm{B}, 5 \%$ solution in barbiturate buffer (pH 8.6, I o.04). I $5 \mathrm{~min}$ at $20 \mathrm{~mA}$. Stain: Amidoblack Io B. The positive electrode is to the right.

Although therefore no distinct separate bands were observed in electrophoretic and ultracentrifugal runs, the results showed Fraction B to be far from homogeneous. This polydispersity may be clearly demonstrated by subjecting the purified allergen to agar-gel electrophoresis according to WIEME ${ }^{5}$ (Fig. 3).

It is noteworthy that the complex glycoprotein structure of the allergen molecules is in agreement with the general nature of inhalant allergens ${ }^{2}$. The evidence obtained thus far would seem to indicate that the inhomogeneity of the purified allergen is mainly the result of a different degree of carbohydrate binding by the individual molecules, a phenomenon which has also been observed for other inhalation-type allergens.

Full chemical and clinical details of this work will be reported elsewhere.

Our thanks are due to Mr. H. J. VREEMAN for the ultracentrifugal analyses and to Miss J. JANSEN for technical assistance.
Dermatological Department, Academic Hospital, State University, I. Berrens Utrecht (The Netherlands) E. YounG

\footnotetext{
1 F. Widal, P. Abrami and E. Joltrain, Presse méd., 30 (I922) 34 I.

${ }^{2}$ L. BERRENS, Allergie $u$. A sthma, 8 (1962) 75 .

${ }^{3}$ W. Storm van LeEUWen, Ther. d. Gegenw., 65 (1924) 97.

4 J. BRÜCKNER, Biochem. J., 6o (1955) 200.

5 R. J. WIEME, Clin. Chim. Acta, 4 (I959) 317.
}

Received July I4th, I962 